\title{
A RELAÇÃO ENTRE O DIREITO DE PROPRIEDADE E O DIREITO À MORADIA NA CONSTITUIÇÃO FEDERAL DE 1988
}

\author{
THE RELATIONSHIP BETWEEN THE PROPERTY RIGHTS AND THE RIGHT TO \\ HOUSING IN THE FEDERAL CONSTITUTION OF 1988
}

\author{
${ }^{1}$ Cláudia Mansani Queda De Toledo \\ ${ }^{2}$ Carolina Baracat Mokarzel
}

\section{RESUMO}

É objeto deste estudo a apresentação de considerações a respeito da relação existente entre o direito de propriedade e o direito à moradia, que por ocasião das alterações assentadas no texto Constitucional quanto ao direito de moradia inauguram uma nova fase no tratamento do direito de propriedade e estabeleceram parâmetros legislativos à efetivação do desenvolvimento urbano, enquanto elementos de mediação para a efetivação das normas constitucionais. O diálogo entre estes institutos chama a atenção de todos, tendo em vista as ressignificações ocorridas após a Constituição Federal de 1988 prever por meio de Emenda Constitucional 64, de 4 de fevereiro de 2010, a inclusão como direito social da moradia, em seu artigo $6^{\circ}$, o que justifica o objetivo de delinear aproximações teóricas entre estes institutos - direito de propriedade e moradia tendo em vista também a questão da incontestável constitucionalização do direito, para então desenvolver um novo olhar aos mesmos, à luz dos parâmetros legais, doutrinários e também jurisprudenciais, a fim de melhor compreender a extensão e compreensão do direito à moradia, sobretudo, na medida em que coexiste na ordem constitucional e, por muitas vezes, colocam-se em colisão.

Palavras-chave: Direito de propriedade, Direito à moradia, Função social, Estado

\footnotetext{
${ }^{1}$ Doutora em Sistema Constitucional de Garantia de Direitos pelo Instituição Toledo de Ensino - ITE, São Paulo (Brasil). Professora de Direito pela Faculdade de Direito do Sul de Minas - FDSM, Minas Gerais (Brasil). E-mail: quedatoledo@uol.com.br

2 Bacharel em Direito pela Faculdade em Campinas - FACAMP, São Paulo (Brasil).

E-mail: carolmokarzel@gmail.com
} 


\section{INTRODUÇÃO}

Destaca-se a importância do tema, tendo em vista os novos parâmetros normativos para a efetivação do desenvolvimento urbano acerca do direito de propriedade e de moradia, prescritos e orientados no cenário legislativo por meio da inserção constitucional do direito à moradia, bem como, com as recentes modificações pela edição da Lei Federal $n^{\circ}$. 10.257, de 10 de julho de 2001 (Estatuto da Cidade), que regulamentou as disposições dos artigos 182 e 183 do texto maior.

A questão em foco neste estudo diz respeito a relação entre o direito de propriedade e o de moradia, em especial quanto aos conflitos atuais que se estabeleceram desde as disposições editadas pelo Estatuto da Cidade e frente à introdução das novas regras advindas com o Diploma Civilista de 2002, no que tange à propriedade, seus desdobramentos no Estatuto da Cidade, tudo no sentido de melhor compreender o instituto e desmistificar as polêmicas constitutivas em caso de colisão entre os dois direitos ditos fundamentais, sem o objetivo, no entanto, de esgotamento do tema, tendo por certo que os dispositivos constitucionais, se adotarmos a teoria da imediaticidade ${ }^{1}$ das normas constitucionais, sequer seria necessário a menção à referida legislação infra-constitucional.

Em análise mais ampla vê-se que o assunto abordado neste trabalho consta de um tema situado numa zona de incerteza e de inegável conflito dialético entre os quais, de um lado existe o Estatuto da Cidade e, de outro, o Código Civil vigente, sem deixar as escuras os princípios constitucionais que informam o direito de propriedade e moradia, inscritos na Constituição Federal de 1988.

Em dimensão de direitos fundamentais, nos quais estão inseridos o direito à moradia e à propriedade, se mostra inegável que, dado serem direitos autônomos, crível é que se constate na convivência em sociedade, assim como entre outros direitos fundamentais, colisões que devem ser resolvidas pelo direito de modo a assegurar a importância de cada um conforme o que foi dado pelo texto constitucional.

O critério de escolha do tema foi dado pela importância que a temática ganhou nos últimos anos em decorrência das alterações normativas instauradas no campo do direito de

\footnotetext{
${ }^{1}$ Nos ensina Wilson Steinmetz, quando do estudo da vinculação dos particulares a direitos fundamentais, que há diversas teorias desenvolvidas especialmente na doutrina alemã nesse sentido e, dentre elas a de que a norma constitucional não necessita de mediação legislativa para a sua efetividade, teoria imediata, não obstante não seja
} 
propriedade e da moradia, para então buscar-se um redimensionamento dos conceitos e do alcance dos referidos institutos, tudo para a melhor compreensão de ambos, sempre sob a ideia estruturante de proteção e garantia dos direitos fundamentais.

Para tanto, esse trabalhos divide-se em dois capítulos que irão destacar o seu objeto da seguinte forma: O primeiro capítulo deve definir o direito de propriedade e de moradia, permitindo-lhes um diálogo comparativo. O segundo, por sua vez, deve analisar os institutos pela ótica da colisão de direitos fundamentais, como se controversos entre si, a fim de se estabelecer parâmetros para uma resposta estatal em caso de colisão.

A pesquisa lançada realizou-se por meio de pesquisa bibliográfica, com a busca de respostas adequadas para compreender os entraves do problema dessa suposta impossibilidade de conciliação entre os mencionados direitos, dirigindo-se o trabalho para uma abordagem conceitual e valorativa sobre a temática. Considerou-se igualmente as estreitas opiniões dos doutrinadores e juristas, bem como, a relação dos fatores implicados, dentre outras questões que se mostram pertinentes no desenvolvimento da temática e de sua conclusão.

o objeto do referido artigo o desenvolvimento das teorias sobre a efetividade da norma e seus instrumentos normativos. 


\section{DO DIREITO DE PROPRIEDADE E MORADIA}

\subsection{Conceito de propriedade e o direito}

Inicia-se essa abordagem conceitual trazendo a lume a etimologia do instituto da propriedade e, frente a isso, parte-se da análise da doutrina clássica na qual se contempla o sentido etimológico do termo propriedade, sob a ótica de alguns estudiosos que acreditam que o vocábulo tem origem no latim "proprietas", derivado de "proprius", que significa o que pertence a uma pessoa. Nesse passo, acrescenta-se que a propriedade indica "toda a relação jurídica de apropriação de certo bem corpóreo ou incorpóreo" (COSTA, 2011, p. 01).

Noutras banda, discorrendo sobre o conceito de propriedade encontram-se outros estudiosos que defendem que o termo propriedade, ao contrário, deriva do termo "domare", o que indica "sujeitar ou dominar". Nada obstante, embora tenho a legislador do diploma Civilista em seus dispositivos empregado o vocábulo "domínio" de forma distintiva do termo propriedade, habitualmente, emprega-se tais termos como sendo sinônimos (MONTEIRO, 1985, p. 88).

Entretanto, tendo em vista a tarefa árdua de traçar um conceito para o vocábulo propriedade, o jurista SCIALOJA (Apud., COSTA, 2011, p. 01) nos dá conta de que é viável conceituá-lo, conforme as três opções:

a) limitar a propriedade e seus elementos constitutivos: direito de usar, gozar e dispor;

b) enfatizar que a propriedade vem a ser a exteriorização da vontade livre do proprietário; e,

c) relevar o momento estático da relação jurídica da propriedade sem preocupar-se com a possível manifestação da vontade do proprietário.

O Código Civil brasileiro em seus dispositivos que tratam a questão da propriedade, adotou como regra a primeira opção mencionada nas linhas anteriores, ou seja, tomaram como alicerce para delimitar o conteúdo da propriedade, as prescrições relativas aos poderes do proprietário, que são os direitos de usar, gozar e fruir de sua propriedade (COSTA, 2011, p. 01).

Destaque-se que, para Maria Helena DINIZ (2003, p. 848), em linhas gerais acerca da propriedade tem-se que se trata do direito "que a pessoa física ou jurídica tem de usar, gozar, dispor e reaver". 
Por seu turno, ao contemplar a obra sobre o conceito de propriedade, o autor Clóvis BEVILÁQUA (2003, p. 127) preceituava que se trata do "poder assegurado pelo grupo social à utilização dos bens da vida física e moral"

Como visto, a teor da norma civilista vigente, assim como outras versões codificadas em ordenações ocidentais, como, por exemplo, o Código Civil alemão, a definição legal de propriedade não se encontra prescrita, restando descrito apenas o seu conteúdo, ao qual, foram ministrados subsídios para sua exata concepção, ao passo que, referidos elementos compõem a integralização dos preceitos jurídicos que traduzem os valores essenciais de uma sistemática jurídico, dotada de funções normativas (COSTA, 2011, p. 01).

Consoante outros os ensinamentos dados pela professora Maria Helena DINIZ (2000, p. 103) sobre a propriedade, na qual de forma categórica define que "é a relação fundamental do direito das coisas, abrangendo todas as categorias dos direitos reais sobre coisas alheias, sejam direitos reais limitados de gozo ou fruição, sejam os de garantia ou de aquisição”.

Destarte, com efeito, no âmbito do escorço histórico do instituto da propriedade proposto neste capítulo, afirma-se, sob a ótica da doutrina tradicional que ter propriedade "é uma condição natural do homem". Qualquer que seja a ideologia adotada e do período histórico utilizado para a contemplação, inegavelmente esse estado relativo à pessoa, vai além de uma simples concepção espiritual, ou de uma conceituação jurídica (CAMPOS, 2010, p. 01).

Depreende-se dos relatos históricos que as primeiras noções de propriedade surgiram no contexto do direito em relação aos bens móveis, principalmente em relação os frutos colhidos das árvores, obtidos com a caça e a pesca para fins de alimentação, de tal modo, no tocante aos itens como ferramentas utilizados no cotidiano dos homens e as armas utilizadas para sua defesa também são enquadrados nesta concepção de propriedade (CAMPOS, 2010, p. 01).

Como dito anteriormente neste contexto, acerca do conceito doutrinário e a compreensão legal do instituto da propriedade e o direito a ela inerente, o que se verifica é que até atingir a concepção moderna de propriedade privada, sofreram inúmeras influências no curso da historia dos vários povos, desde a antiguidade. A história da propriedade é decorrência direita da organização política (VENOSA, 2004, p. 169).

Em nosso país, o conceito jurídico de propriedade é o mesmo desde antes da promulgação do Código Civil de 1916. Nem por isso, a par das noções programáticas das várias Constituições que veicularam ao longo dos anos no país, concebe-se a propriedade atualmente nos tribunais da mesma forma que no início do século 20. Tendo em vista a 
ressignificação histórica dos institutos civilistas, o juiz, ao proferir sentença, deve retratar a absorção do sentido social de sua realidade temporal e espacial e, necessariamente não expressar um sentimento individual de justiça, a fim de se evitar a substituição do legislador, ao criar lei individual e desprovida dos ditames constitucionais envoltos na ideia de solidariedade social. Não pode o julgador substituir o direito; tem o dever de ser seu interprete. Nessa interpretação e integração das normas reside o papel criador do magistrado, como orienta Venosa (2004, p. 173).

Em regra, a própria expressão de gozo e disposição da propriedade de forma absoluta desde o Código de Napoleão, já não encontrava na França a correspondência nas leis posteriores que naquele país trataram do instituto. Sempre se entendeu que qualquer direito tido como absoluto, será sempre a sua própria negação. Cuida-se nesse aspecto do conceito de abuso de direito. A novel versão do diploma civilista, não bastasse à regra geral acerca do abuso de direito, enuncia regra específica quanto aos excessos quando se procura entender o direito de propriedade.

Toda a propriedade, ainda que resguardado o direito de seu titular, deve atender a uma função social. Não se olvide, de que este é o fundamento que legitima a convivência recíproca de diversos institutos fundamentais inseridos na Constituição. E assim, nessa órbita funcional, a norma civilista vigente, após descrever os poderes inerentes ao proprietário, dispõe:

Art. 1.228.

(...).

$\S 1^{\circ} \mathrm{O}$ direito de propriedade deve ser exercido em consonância com as suas finalidade econômicas e sociais e de modo que sejam preservados, de conformidade com o estabelecido em lei especial (...).

Presentes estão nessas dicções princípios afastados do individualismo histórico que não somente buscam coibir o uso abusivo da propriedade, como também, procuram inseri-la no contexto de utilização para o bem comum.

Reduzindo-se a propriedade aos seus elementos essenciais positivos, ter-se-á: direito de usar, gozar, dispor e reivindicar, que, como assevera Diniz (2003, p. 784), se traduz da seguinte forma:

"Jus utendi": o direito de usar da coisa é o de tirar dela todos os serviços que pode prestar, dentro das restrições legais, sem que haja modificações em sua substancia. 
"Jus fruendi": o direito de gozar da coisa exterioriza-se na percepção dos seus frutos e na utilização de seus produtos. É, portanto, o direito de explorá-la economicamente.

"Jus disponendi": o direito de dispor da coisa é o poder de aliená-la a título oneroso ou gratuito, abrangendo o poder de consumi-la e o de gravá-la de ônus reais ou de submetê-la ao serviço de outrem.

"Rei vindicatio": o direito de reivindicar a coisa é o poder que tem o proprietário de mover ação para obter o bem de quem injusta ou ilegalmente o possua ou o detenha, em razão do seu direito de seqüela.

Mais adiante, sobre essa questão em foco, o referido jurista Venosa (2004, p. 179) em sua obra sobre "direitos reais", descreve com sapiência que a faculdade de usar a que alude a definiçãa de propriedade se trata, em regra, de colocar a coisa a serviço do titular sem lhe alterar a substancia. Nesse passo, tem-se que o proprietário usa seu imóvel quando nele habita ou permite que terceiro o faça. No caso deste último elemento o uso inclui também a conduta estática de manter a coisa em seu poder, sem utilização dinâmica. Usa de seu terreno o proprietário que o mantém cercado sem qualquer utilização. O titular serve-se, de forma abrangente, da coisa, acrescenta o autor.

Por sua vez, o verbo gozar do bem significa extrair dele benefícios e vantagens. Isso revela que o titular do bem terá direito à percepção de frutos, tanto naturais como civis. Nada obstante, em relação à faculdade de dispor, tem-se o poder de consumir o bem, alterar-lhe a substancia, aliená-lo ou gravá-lo. É o poder mais abrangente, pois quem pode dispor da coisa, dela também poderá usar e gozar. Essa faculdade caracteriza efetivamente o direito de propriedade, pois o poder de usar, gozar fatalmente não pode ser atribuído a quem não seja proprietário (VENOSA, 2004, p. 179).

Nada obstante, à melhor análise do tema, observa-se que no inciso imediatamente posterior do referido artigo, há a indicação do legislador constituinte quanto à função social da propriedade, o que leva uma parte importante da doutrina a mencionar que a propriedade protegida como direito fundamental pela Carta magna é tão somente aquela que deve satisfazer o requisito disposto em aludido dispositivo legal, qual seja: "que cumpre sua função social". Essa afirmação, por seu turno, encontra suporte, além dos demais incisos daquele artigo constitucional, noutro suporte pelo disposto no art. 170, incisos II e III, que trata a respeito dos princípios gerais da atividade econômica, conforme preleciona Venosa (2004, p. 179).

Veja-se o teor do dispositivo: 
Art. 170. A ordem econômica, fundada na valorização do trabalho humano e na livre iniciativa, tem por fim assegurar a todos existência digna, conforme os ditames da justiça social, observados os seguintes princípios:

(...);

II - propriedade privada;

III - função social da propriedade;

Diz-se a respeito do direito à propriedade, enquanto direito fundamental assegurado pela norma constitucional, que este encontra-se no rol dos direitos e deveres individuais e coletivos dados pelo art. $5^{\circ}$ da Constituição Federal de 1988, no inciso XXII, que impõe a garantia a esse direito ao estabelecer os limites exclusivos de sua utilização.

Lembre-se que a convivência de direitos fundamentais no âmbito constitucional passou a limitar algumas das características fundamentais da propriedade, como anotado no objeto deste trabalho, o próprio principio da função social da propriedade estabelecido pelo já citado inciso XXIII, do art. $5^{\circ}$, acrescido também da própria possibilidade de limitação pelas requisições civis e militares conforme o inciso XXV do mesmo artigo. ${ }^{2}$

Ainda mais, de se ressaltar que o próprio caráter de perpetuidade da propriedade poderá igualmente ser limitado, quando se analisa institutos como a desapropriação, usucapião e também do confisco, nos termos da norma maior.

Com vistas ao reforço da função social, a manifestação de SEN E KLILSBERG, segundo os quais é preciso cautela quando se raciocina no sentido de privilegiar os interesses individualmente considerados, quando analisa a necessidade de observância à racionalidade pública, nos seguintes argumentos:

“...a racionalidade requer que os indivíduos tenham a vontade política de ir além dos limites de seus próprios interesses específicos. Mas ela também impõe exigências sociais para ajudar um discernimento justo...” (2010, p. 54).

\footnotetext{
${ }^{2}$ Art. $5^{\circ}$ Todos são iguais perante a lei, sem distinção de qualquer natureza, garantindo-se aos brasileiros e aos estrangeiros residentes no País a inviolabilidade do direito à vida, à liberdade, à igualdade, à segurança e à propriedade, nos termos seguintes:

(...);

XXIII - a propriedade atenderá a sua função social;

(...);

XXV - no caso de iminente perigo público, a autoridade competente poderá usar de propriedade particular, assegurada ao proprietário indenização ulterior, se houver dano;
} 
Desta feita, impõe-se afirmar que a propriedade enquanto direito absoluto garantido pela Constituição Federal é uma instituição submetida ao regime do direito público (SILVA, 2005, p. 265) e que não mais subsiste na realidade da sociedade atual. Fatalmente o que existe ainda são as propriedades que são chamadas de "puras", isto é, aquelas que não cumprem com a sua função social e as que cumprem com a sua função social nos termos imposto pelo ordenamento constitucional.

Segundo preleciona o jurista Marcelo Magalhães Peixoto (2002, p. 443) a despeito da teoria da função social da propriedade o que salta aos olhos modernamente é que não tem mais a conotação do direito de propriedade com moldes romanos, com aquele formato absoluto de outrora, contrariamente, se percebe com o argumento do poder outorgado para seu exercício e utilização social, considerado como uma função não individual, mas sim, de cunho social.

Ademais, ainda o mesmo autor afirma que o proprietário, efetivamente, tem o dever de exercer o direito de propriedade de acordo com os interesses da coletividade, cabendo-lhe apenas direcionar-lhe o exercício de acordo com as orientações da política social de cada Município em que estiver situado o imóvel a ser tributado em respeito à função social da propriedade.

Observando com olhar mais atento percebe-se que o direito de propriedade sempre poderá ser limitado quando houver um interesse maior, que é o interesse social, como pode ser contemplado pela leitura de alguns dispositivos constitucionais indicados alhures, sendo que, desta feita, considera-se o atendimento a função social da propriedade um princípio que coexiste para estabelecer um equilíbrio entre os valores deste principado com o princípio da propriedade privada.

\subsection{Conceito de moradia e o direito}

Mister se faz aqui asseverar que os direitos humanos e direitos fundamentais destinamse cabalmente, à assegurar a dignidade à existência humana, na medida que criam uma tendência inevitável em reconhecê-los com o mesmo significado, apesar disso, não podem ser compreendidos como sendo sinônimos, posto que a denominação distinta de cada um não é decorrente de mero preciosismo acadêmico.

Dessa forma, Sarlet (2005,p.35) diz que os direitos fundamentais determinam as posições jurídicas básicas reconhecidas como tais pelo Direito Constitucional positivo de um certo Estado, em um determinado momento histórico. Já os direitos humanos podem ser 
caracterizados como os direitos básicos da pessoa reconhecidos pelo Direito Internacional positivo ou consuetudinário e que portanto, transcendem os limites de territórios nacionais (SAMPAIO, 2004, p. 08 )

Desde 2002, o Programa Nacional de Direitos Humanos brasileiro indica que consideram-se direitos humanos o conjunto de direitos universais, indivisíveis e interdependentes, que compreendem direitos civis, políticos, sociais, culturais e econômicos, de forma que a amplitude a eles conferida na recomendação nacional sobre direitos humanos não pode apequenar-se, tornar-se diminuta.

Verifica-se que a colocação do rol de direitos fundamentais logo na abertura do texto constitucional representa a real intenção do legislador constituinte de lhes emprestar um significado particular. $\mathrm{O}$ alcance dado ao texto normativo de um modo geral, reforça a posição de destaque que o constituinte quis outorgar a esses direitos demonstrando sua positivação e relevância para o direito nacional.

Vale dizer, que os direitos fundamentais são classificados pela maioria da doutrina em três gerações ou dimensões. Colacionados na primeira geração estão aqueles que abarcam os direitos civis e políticos inerentes a cada cidadão e representam uma garantia individual que limita a intervenção estatal na esfera privada, os chamados direitos de liberdade. Na segunda dimensão, estão os direitos ligados a uma atuação positiva do Estado, quais sejam aqueles ligados diretamente à busca da equalização, ou seja, da igualdade. São direitos que o cidadão tem de receber uma prestação estatal que lhe garanta uma vida digna, de forma efetiva e não só formal. Na terceira dimensão estão os direitos relacionados à solidariedade e à fraternidade, tais como a paz, o meio ambiente e a autodeterminação dos povos. Alguns autores ainda mencionam direitos de quarta e quinta geração, mas aqui não nos cabe discutir tal classificação.

O direito de moradia está enquadrado no rol dos direitos humanos de segunda geração. Tratam-se dos direitos sociais, quais sejam aqueles que prescrevem para o Estado o dever de atuação em prol do indivíduo. Os direitos de segunda geração, na ótica de Celso de Mello (apud MORAES, 2007, p. 25) são aqueles "que se identificam com as liberdades positivas reais e concretas, acentuando o princípio da igualdade". Trata-se esta dimensão dos direitos sociais $^{3}$, econômicos e à vida, ensina Castilho (2004, p. 71).

Pode-se dizer que o direito à moradia encontra guarida no ordenamento jurídico brasileiro desde antes de estar previsto na constituição. Exemplo disso, vem do direito civil

\footnotetext{
3 Entre os direitos chamados sociais, incluem-se aqueles relacionados com o trabalho, o seguro social, a subsistência, o amparo à doença, à velhice, etc.
} 
que protege o bem de família e prevê o direito real de habitação. Ambos podem refletir a antiga preocupação do legislador em proteger e conferir uma morada aos indivíduos.

Em sua origem, o aludido direito à moradia no panorama brasileiro, remonta à Constituição Federal editada em 1934, vez que nem a versão de 1824, tampouco a Constituição Republicana de 1891 estabeleciam normas que de forma expressa garantissem esse direito. No entanto, a última constituição citada prescrevia em um de seus dispositivos "que a casa era o asilo inviolável do indivíduo, sendo possível nela entrar somente com autorização de seu morador", essa regra acabou sendo reproduzida em textos constitucionais vindouros, segundo ensina Pansieri (2008, p. 112) e pode ser considerada como uma forma de proteção à morada do indivíduo.

Em equivalência, com o advento da Carta Magna de 1988 o constituinte pátrio veio finalmente a estabelecer critérios objetivos para fins de aferir-se o cumprimento da função social de uma determinada propriedade.

Encerrando por fundamento a máxima da dignidade da pessoa humana, a atual versão constitucional fez menção categoricamente ao direito à moradia no art. 183, in verbis:

Art. 183. Aquele que possuir como sua área urbana de até duzentos e cinquenta metros quadrados, por cinco anos, ininterruptamente e sem oposição, utilizando-a para sua moradia ou de sua família, adquirir- lheá o domínio, desde que não seja proprietário de outro imóvel urbano ou rural.

Assim vê-se que em linhas gerais o instituto recebia os contornos de direito, mas foi somente em 2000, com a edição da Emenda Constitucional n. ${ }^{\circ}$ 26/2000, que foi conferido ao direito à moradia o status de direito fundamental social, com a sua inclusão no art. $6^{\circ}$ da Constituição Federal vigente.

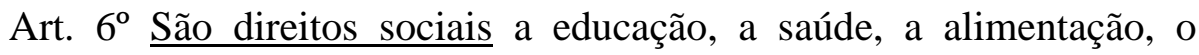
trabalho, a moradia, o lazer, a segurança, a previdência social, a proteção à maternidade e à infância, a assistência aos desamparados, na forma desta Constituição. (Grifou-se)

Ademais, em sua definição, o direito de moradia, consiste na ocupação de determinado local como se sua residência fosse, para fins de habitação. Ressalte-se que não se trata precisamente de um direito à casa própria, mas sim de uma garantia que o indivíduo possui, por força constitucional, de ter uma guarida permanente para ele e para sua família. 
Buscando outras definições, traz-se a lume o entendimento ofertado pelo autor José Reinaldo de Lima Lopes (apud PANSIERI, 2008. p. 112) que afirma que "o Direito à Moradia inclui o direito de ocupar um lugar no espaço, assim como o direito às condições que tornam este espaço um local de moradia, de tal sorte que morar constitui um existencial humano", tendo o aludido autor embasado sua definição no conceito estabelecido acerca do direito à moradia pela Observação Geral n. ${ }^{\circ} 4$ do Comitê de Direitos Econômicos, Sociais e Culturais das Nações Unidas, que faz a seguinte indicação:

O direito a uma moradia adequada significa dispor de um lugar onde se possa asilar, caso o deseje, com espaço adequado, segurança, iluminação, ventilação, infraestrutura básica, uma situação adequada em relação ao trabalho e o acesso aos serviços básicos, todos a um custo razoável (PANSIERI, 2008. p. 112).

Outra definição interessante foi dada pelo autor Flávio Pansieri (2008, p. 51) ao esclarecer que:

O Direito à Moradia consolidado como Direito Fundamental e previsto expressamente como um Direito Social no artigo $6^{\circ}$ da Constituição brasileira, em correspondência com os demais dispositivos constitucionais, tem como núcleo básico o direito de viver com segurança, paz e dignidade e, segundo Pisarello, somente com a observância dos seguintes componentes se encontrar plenamente satisfeito: segurança jurídica da posse; disponibilidade de serviços e infraestrutura; custo de moradia acessível; habitabilidade; acessibilidade; localização e adequação cultural.

Enquanto cabedal social consagrada pelo ordenamento jurídico pátrio, Gilson Luiz Inácio (2002, p.45), que a moradia por se enquadrar como direito social deve então "ser implementada progressivamente pelo Poder Público", que tem a incumbência de adotar posturas que de maneira efetiva venham a concretizar o acenado direito, alcançando, desta feita, além do primado da justiça social, a justiça universal, ajustando os excessos da autonomia da vontade em prol dos interesses coletivos, assevera.

Por seu turno o autor José Reinaldo Lima Lopes (2006, p. 85-86) em seu ensinamento foi inovador ao maximizar que o direito à moradia encontra fundamento "na ideia de direito à vida". Sob a ótica desse autor restou assentado que o "fundamento reside na marginalidade geográfica, que, por sua vez, é gerada pela marginalidade econômica". De 
forma contundente o citado jurista defende em suas lições “que a exclusão espacial não quer dizer inexistência de abrigos contra intempéries, e que a questão da moradia não é resolvida com a simples distribuição de casas".

$\mathrm{Na}$ seara do Brasil, tem-se que o direito à moradia guarda relação direta com a estrutura que envolve as instituições financeiras e as construtoras, com o patrocínio do ente Estatal. Esse modelo de financiamento da construção acarretou a especulação urbana e, consequentemente, um complexo financeiro-industrial de apropriação da cidade (LOPES, 2006. p. 70-71).

Ademais, ao volver os olhares ao conceito do direito à moradia, as lições de José Afonso da Silva (2005, p. 280), dão conta que:

Direito à moradia significa, em primeiro lugar, não ser privado arbitrariamente de uma habitação e de conseguir uma e, por outro lado, significa o direito de obter uma, o que exige medidas e prestações sociais adequadas à sua efetivação (...)

No mesmo sentido, mas com palavras distintas esta a manifestação de Heriberto Maciel (2000, p. 43) que aduz:

O direito mínimo (...) é o de habitar com dignidade, o que é ponto de reivindicação política dos movimentos sociais. Isso significa também que direito à qualidade mínima que o morar exige, ou seja, o cidadão ter casa ou apartamento, mesmo que locado, com acesso ao transporte para o trabalho e algum lazer, bem como os demais equipamentos sociais e urbanos indispensáveis, como serviços essenciais à água potável, drenagem, ruas transitáveis e iluminadas o ano todo.

$\mathrm{O}$ direito à moradia teve sua fundamentalidade reconhecida e reforçada com o advento da EC 26/2000, ainda que muitos doutrinadores já a considerassem um direito fundamental implícito amparado pelo dispositivo que prevê a competência administrativa de todos os entes federativos para a promoção de programas construção de moradias e melhorias das condições habitacionais e de saneamento básico (CF, art. 23, inciso IX).

Impõe-se afirmar que, em relação ao direito de propriedade, que sua definição pode abranger duas dimensões que são, de um lado positiva e, de outro, negativa.

Em sua dimensão positiva, a moradia não se traduz, necessariamente, no direito à propriedade imobiliária ou no direito de ser proprietário de um imóvel. De regra a limitação e escassez de recursos, infelizmente, impede que esse direito seja implemento no seu grau 
máximo desejável. A fundamentalidade do direito à moradia envolve a inviolabilidade de seu núcleo, a fim de garantir aos desamparados a oponibilidade em face do Estado, enquanto direito subjetivo, ao lado dos demais direitos sociais elencados no artigo $6^{\circ}$ da Constituição Federal de 1988.

Nesse sentido, é por meio dessa dimensão de fundamentalidade dos direitos sociais que se pode conferir em favor da cidadania as próprias liberdades sociais, haja vista que o Estado tem a obrigação de proporcionar o bem estar da sociedade.

A plena garantia do direito de moradia pressupõe uma moradia em suas dimensões, condições de higiene e capaz de preservar a intimidade das pessoas e acima de tudo, assegurar a elevação de sua dignidade enquanto pessoa humana.

Em relação a sua dimensão negativa, este direito protege a moradia contra ingerências indevidas do estado e outros particulares. De conformidade com o entendimento do $\mathrm{STF}^{4}$ acerca da penhorabilidade do bem de família do fiador em contratos de locação não ofende o art. $6^{\circ}$ da $\mathrm{CF}$, mas com ele se coaduna por viabilizar o direito à moradia, facilitando e estimulando o acesso a habitação arrendada, constituindo reforço das garantias contratuais dos locadores, e afastando, por conseguinte, a necessidade de garantias mais onerosas, destacou Sarmento (2010, p. 997).

Desta feita, a partir da análise do texto constitucional, verifica-se que o legislador simplesmente prognosticou o direito à moradia sem, contudo, fazer qualquer ampliação no texto da lei relativo ao alcance do instituto, conteúdo e significado, o que faz com que, embasado neste argumento, uma parcela da doutrina sustente se tratar aludido direito de mera norma programática desprovida, por tal razão, de eficácia. Todavia, mesmo que a Constituição Federal não tenha estabelecido explicitamente, qual o conteúdo e também o significado deste direito, ainda assim, o ordenamento jurídico fornece quais são os elementos que possibilitam alcançar essa determinação.

Neste rumo, pode-se ainda aqui afirmar com base nas lições doutrinárias tradicionalistas que o direito à moradia deve ser combinado como direito a uma moradia com dignidade. Parece razoável a despeito deste tema que a expressão "digna" foi abolida pelo legislador, posto que inexista como conceber-se, num Estado Democrático de Direito como é o caso do Brasil um direito que não represente o exercício de uma vida digna ao seu povo.

Tal se faz imperioso posto que a dignidade é um valor subjacente às numerosas regras de direito, notadamente ao lado da indicação dos direitos fundamentais sociais, daí a

\footnotetext{
${ }^{4}$ RE 407.688/SP, rel. Min. Cezar Peluso (08.02.2006).
} 
razão de ser da proibição de toda ofensa à dignidade da pessoa, eis que ela representa uma questão de respeito ao ser humano, e que leva o direito positivo a protegê-la, a garanti-la e a vedar atos que podem de algum modo levar à sua violação, inclusive na esfera dos direitos sociais (MORAES, 2007, p. 46-47).

Nesse sentido, Alexandre de Moraes (2007, p. 128), nos dá conta que:

A dignidade da pessoa humana é um valor espiritual e moral inerente à pessoa, que se manifesta singularmente na autodeterminação consciente e responsável da própria vida e que traz consigo a pretensão ao respeito por parte das demais pessoas, constituindo-se em um mínimo invulnerável que todo estatuto jurídico deve assegurar, de modo que apenas excepcionalmente possam ser feitas limitações ao exercício dos direitos fundamentais, mas sempre sem menosprezar a necessária estima que merecem todas as pessoas enquanto seres humanos.

Fatalmente isso implica em dizer que o direito à moradia sugere uma série de outros fatores que a ela devem estar vinculados. Nada obstante a maior problemática que é enfrentada neste âmbito diz respeito à possibilidade de interpretações limitativas que poderiam, até mesmo, levar a supressão do direito constitucionalmente previsto.

Contudo, é de se ter em mente que, no caso particular do direito à moradia, essa omissão constitucional quanto à vinculações como por exemplo, a orçamentária, se mostra bastante prejudicial a sua efetividade social, como entendem alguns juristas, haja vista que esta omissão se reflete também no âmbito dos tratados, das legislações extravagantes, bem como, por uma interpretação sistemática à luz do princípio da dignidade da pessoa humana.

Como dito alhures a dignidade da pessoa humana, enquanto primado constitucional representa, em derradeira análise, "o valor maior vinculante de toda ordem jurídica, quer esteja expressamente positivado" (MATEUS, 2005, p. 01). Denota-se, deste modo, que a finalidade do Estado Social encerra-se pela busca de uma existência calcada na digna para a sua população, porquanto, conforme sustenta Rizzatto Nunes (2003, p. 148), “(...) o que interessa mesmo é que se possa garantir a vida, mas uma vida digna".

Há de se notar que a dignidade da pessoa humana, máxima insculpida pela Carta Política em seu art. $1^{\circ}$, inciso III, não foi criada pelo Legislador Constituinte, mas sim, recepcionada por ele e, atuando sobre toda a ordem jurídica, o princípio em apreço funciona como verdadeira cláusula geral de tutela da pessoa, que contém em seu cerne a igualdade, a integridade psicofísica, a liberdade e a solidariedade, de modo a proteger o ser humano de 
forma integral, inclusive em seu estagio de desenvolvimento e formação social (BULOS, 2003, p. 37).

É nesta seara que se pode anotar que os direitos fundamentais encontram-se alcançando, por meio da ordem jurídico-constitucional, a proteção e a promoção da dignidade da pessoa humana, sendo esta, conforme Ferreira Santos (1999, p. 132), “o núcleo essencial dos direitos fundamentais".

Neste rumo, é crível afiançar que a satisfação deste princípio maior da dignidade insculpido pela Carta Magna encontra-se na dependência da realização de uma série de outros direitos, como já posto nesta textualização.

No mesmo sentido um posicionamento pertinente nesta textualização é dado por Ingo Sarlet (2007, p. 366) ao dar conta que segue:

(...) o que se pretende sustentar de modo mais enfático é que a dignidade da pessoa humana, na condição de valor (e princípio normativo) fundamental que atrai o conteúdo de todos os direitos fundamentais, exige e pressupõe o reconhecimento e proteção dos direitos fundamentais de todas as dimensões (ou gerações, se assim preferirmos). Assim, sem que se reconheçam à pessoa humana os direitos fundamentais que lhes são inerentes, em verdade estar-se-á lhe negando a própria dignidade.

Diz-se que a consagração da dignidade humana pelo texto constitucional reforça, ainda o reconhecimento de que a pessoa não é simplesmente um reflexo da ordem jurídica, mas ao contrário, deve constituir o seu objeto supremo na sua relação entre o individuo e o Estado, presumindo as necessidades humanas, aliás, tão evidentes como o direito à moradia como pressuposto de dignidade.

Sustenta-se aqui, apoiados no entendimento de Ingo Sarlet (2010, p. 1034) que o direito de moradia abrange todo conjunto de posições jurídicas vinculadas à garantia de uma moradia digna para a pessoa humana, dentre aos quais se incluem os diretos de moradia e os deveres de proteção deste direito. A garantia plena deste direito pressupõe uma moradia adequada em suas dimensões, capaz de preservar a intimidade e privacidade das pessoas.

É oportuno dizer que, agir com respeito à dignidade da pessoa é uma forma de garantir à consecução dos demais princípios, direitos e garantias fundamentais reservados a pessoa pela Carta Magna. Mas a grande questão que aqui se vislumbra é a atuação do Estado para as crianças e adolescentes em ofensa a tal princípio quando o Poder Público fecha os olhos ao problema de ordem infracional. 


\section{DIREITO À MORADIA X DIREITO DE PROPRIEDADE}

\subsection{Da colisão de direitos}

Neste segundo momento, pretende-se analisar os institutos da propriedade e da moradia pela ótica da possível colisão de direitos fundamentais. $\mathrm{O}$ aparente confronto entre o direito fundamental de propriedade e o direito à moradia pode gerar algumas incertezas, sendo necessário que o Estado e os intérpretes do direito deem uma resposta satisfatória às questões colidentes. Nesse sentido, fundamental o equilíbrio e a ponderação de ambos para que se possa efetivamente buscar uma solução compatível com a regular aplicabilidade de cada um, sem nunca perder de vista o respeito ao princípio da dignidade da pessoa humana.

Desta maneira, ao analisar a questão de maneira mais profunda, observando especialmente o conflito real entre o direito particular de propriedade e o direito de moradia, doutrina e jurisprudência deverão trabalhar na mitigação ou na flexibilização eventual desses direitos para que ambos convivam de forma harmônica, podendo então existir uma solução tecnicamente aceitável, para cada caso concreto.

Estabelecendo uma revisão do direito de moradia e de propriedade com o necessário diálogo comparativo entre ambos, emerge a constatação de que para se firmar a tutela do Estado na garantia desses direitos e, sobretudo, o atendimento do princípio da função social sobre a propriedade, o ente estatal tem por regra o dever e a responsabilidade de criar, implementar e executar políticas públicas de ordenação e pleno desenvolvimento da cidade, de modo a garantir aos seus habitantes a maximização de seus direitos, inclusive os direitos sociais.

Desta feita no intuito de alcançar o efetivo exercício do direito social à moradia e o cumprimento da função social da propriedade em todos os seus aspectos, o legislador conferiu a função social ao imóvel, de onde o Estado há de tutelar, oferecendo parâmetros, aquele que dá uma destinação adequada ao imóvel urbano.

Assim, por sequela da aplicação de políticas públicas que visam proteger e tornar efetivo o exercício do direito social à moradia, emerge a possibilidade legítima dos Poderes do Estado agirem de forma positiva tornando efetivas as ações de proteção ao direito à moradia. Ainda nessa toada, vale ressaltar que a adequação do direito à moradia deve ser respeitada mesmo quando estiver colidindo com outros direitos de igual categoria, de modo a assegurar a garantia plena da moradia em suas dimensões e ainda a maximização da dignidade da pessoa humana. 
Segundo disposição editada pelo o $\S 1^{\circ}$ do art. $5^{\circ}$ da Constituição Federal, as normas definidoras dos direitos e garantias fundamentais têm aplicação imediata na seara nacional, e por força do que estabelece o $\S 2^{\circ}$ do mesmo artigo dispõe que tais direitos e garantias, expressos na Carta Maior, não excluem outros decorrentes do regime e dos princípios por ela adotados.

Ademais, é sabido que no tocante a natureza dos direitos fundamentais não existe regra absoluta, logo, havendo conflito de normas, não há prevalência inata de um diploma sobre o outro, sendo imperioso se realizar a ponderação entre cada um, sob pena de valorização de um em detrimento do outro de modo desatento.

Como se anteviu, de acordo com a essência dos direitos fundamentais e os interesses constitucionalmente protegidos, não são raras as vezes em que entram em rota de colisão exigindo, por consequência, dos operadores do direito e de todos os intérpretes, sobremaneira para o juiz e o legislador, redobrado esforço para a promoção da efetividade dos direitos em disputa. Essa situação de colisão marca inegável relação entre o direito de propriedade e o direito de moradia, na medida em que a plena efetivação de um deles pode, em muitos casos, trazer reflexos negativos a realização do outro.

Em consonância com os apontamentos anteriormente apresentados, pode-se afirmar que o conteúdo e o âmbito de proteção iniciais do direito à moradia incluem a prerrogativa atribuída a toda pessoa de ocupar por tempo razoável um imóvel fisicamente seguro e adequado, capaz de assegurar a plenitude de sua dignidade no que tange o direito aqui abordado. Por essa razão é que o direito de moradia previsto no art. $6^{\circ}$ da $\mathrm{CF}$ pretende garantir que todos os brasileiros possam exercê-lo. Mas não só. Há necessidade que esse direito seja exercido de forma adequada, pois a moradia não representa apenas a caracterização física de um teto, mas sim um local compatível com condições de habitação, segurança e higiene.

Não há o que se falar em estar a moradia comtemplada pelo direito de propriedade. Muitas vezes, o sujeito de direito é proprietário de um bem imóvel que lhe serve como moradia, no entanto são direitos autônomos, independentes. Nesse sentido, são de fácil percepção as possibilidades de concretização do direito de propriedade sem a abrangência do direito de moradia, tal como ocorre na propriedade de bens móveis ou de bens imóveis com finalidade diversa, tais como os com destinação comercial ou terrenos. Por outro prisma, também é evidente a existência autônoma do direito de moradia, sem o direito de propriedade que pode ser consubstanciada, por exemplo, nas locações residenciais. 
Nesse passo é acertado indicar nestas linhas comparativas que, "além do direito de propriedade existe também o direito à propriedade, como uma das possíveis concretizações do direito fundamental social do direito à moradia" (FACCHINI NETO, 2006, p. 82).

Ademais, complementando esse estudo, cumpre distinguir o direito à moradia do direito de propriedade e do direito à propriedade, e para isso aproveita-se das lições de Sarlet (2003, p. 211):

(...) muito embora a evidência de que a propriedade possa servir também de moradia ao seu titular e que, para além disso, a moradia acaba, por disposição constitucional expressa - e em determinadas circunstâncias - assumindo a condição de pressuposto para a aquisição do domínio (como no caso da usucapião especial constitucional), atuando, ainda, como elemento indicativo da aplicação da função social da propriedade, o direito à moradia - convém frisá-lo - é direito fundamental autônomo, com âmbito de proteção e objeto próprios.

Feitas essas considerações, sobressai com alguma nitidez o maior peso exercido pelo direito à moradia em relação ao direito de propriedade. Em realidade, não se está aqui diante de um verdadeiro jogo de ponderação, haja vista que o próprio direito de domínio, por não desempenhar adequadamente a sua função social, pode perder as garantias judiciais e extrajudiciais viabilizadas pelo sistema. Trata-se de uma nova perspectiva dos direitos aqui tratados, que hoje possuem características diretamente relacionadas com a dignidade e consecução da cidade sustentável.

Cumpre ainda ressaltar, no tocante a essa suposta colisão de direitos que frente aos contornos atuais em torno da propriedade, seu âmago possui características com feições mais humanitárias e menos materialistas do que outrora. Nesse sentido, e como consequência da vontade legal de oportunizar a todos os habitantes das cidades o acesso à moradia como um dos principais elementos promotor da concretização de outros direitos humanos conexos e que foram estabelecidos pela norma, é que emergem as novas perspectivas interpretativas e de aplicabilidade do direito de propriedade.

Com relação ao direito à moradia, permite-se destacar ainda neste estudo algumas considerações, onde se constata que o direito à moradia deve ser considerado, bem como reconhecido e, principalmente tutelado como um direito humano inserido dentro da ordem internacional desde a edição da Declaração Universal dos Direitos Humanos. Nesse sentido, não restam dúvidas do seu enquadramento como como um direito humano fundamental, posto 
que o direito à moradia apresenta como outros direitos humanos as mesmas características e atributos.

Nessa toada o importante é ressaltar que os direitos humanos fundamentais relacionam-se diretamente com a garantia de não-ingerência do Estado na esfera individual e a consagração da dignidade humana, tendo um universal reconhecimento por parte da maioria dos Estados, seja em nível constitucional, infraconstitucional, bem como, em nível de direito consuetudinário.

A previsão desses direitos coloca-se em elevada posição hermenêutica em relação aos demais direitos previstos no ordenamento jurídico nacional, apresentando diversas características peculiares, tais como: imprescritibilidade, inalienabilidade, irrenunciabilidade, inviolabilidade, universalidade, efetividade, interdependência e complementaridade definidos, segundo Moraes (2007, p. 22), como:

a) Universalidade: todo ser humano é sujeito ativo desses direitos, independente de credo, raça, sexo, cor, nacionalidade, convicções, ou seja, a abrangência desses direitos engloba todos os indivíduos;

b) Inviolabilidade: referidos direitos não podem ser descumpridos por nenhuma pessoa ou autoridade, sob pena de responsabilização civil, administrativa e criminal;

c) Indisponibilidade ou irrenunciabilidade: os direitos humanos não contemplam renunciabilidade. Dessa característica surgem discussões importantes na doutrina e posteriormente analisadas, como a renúncia ao direito à vida e a eutanásia, o suicídio e o aborto;

d) Imprescritibilidade: os direitos humanos não sofrem alterações com o decurso do tempo, ou seja, possuem caráter eterno;

e) Complementaridade: os direitos humanos devem ser interpretados em conjunto, não havendo critério hierárquico com a finalidade de alcance dos objetivos previstos pelo legislador constituinte; f) efetividade: a atuação do Poder Público deve ser no sentido de garantir a efetivação dos direitos e garantias previstos, com mecanismos coercitivos para tanto, uma vez que a Constituição Federal não se satisfaz com o simples reconhecimento abstrato;

g) interdependência: as várias previsões constitucionais possuem diversas intersecções para atingirem suas finalidades. Assim, por exemplo, a liberdade de locomoção está intimamente ligada à garantia do habeas corpus, bem como previsão de prisão somente por flagrante delito ou por ordem de autoridade judicial competentes;

h) inalienabilidade: é a característica em que se estabelece que não existe possibilidade de transferência dos direitos humanos fundamentais a nenhum título, seja gratuito ou oneroso.

Acrescente-se que tendo em vista o dever de coerência quanto à construção dos direitos humanos no contexto social, pode-se afirmar que funcionam como termômetros da 
ordem vigente em determinado país, pois são eles os formadores do conceito de cidadania no cenário internacional, por colocarem em evidência os condicionamentos econômicos, sociais e políticos que devem ser respeitados e protegidos por cada cidadão.

Por fim, cabe importante menção à relação da fiscalização do direito de propriedade com o Poder de Polícia do Estado. Nas palavras do professor Marçal Justen Filho (2006, p. 393): “O poder de polícia administrativa é a competência administrativa de disciplinar o exercício da autonomia privada para a realização de direitos fundamentais e da democracia, segundo princípios da legalidade e da proporcionalidade".

Nesse sentido, a verificação do respeito às normas que tratam da utilização da propriedade baseia-se no poder de polícia do Estado. Depreende-se então, que o poder de polícia panorama do direito administrativo e, sobretudo, frente ao Estado Democrático de Direito revela-se como importante poder do Estado que, atuando dentro da legalidade, destina-se a condicionar a liberdade, haja vista a possibilidade de assumir papel de dupla característica, ora se apresentando como de instrumento realizador dos princípios do Estado, ora limitando os atos públicos ou privados por meio dos mesmos princípios, sempre com o objetivo de promover a concretização dos direitos fundamentais.

\section{CONCLUSÃO}

O conteúdo abordado neste trabalho é decorrente de uma pesquisa bibliográfica e normativa acerca da temática do Direito de propriedade e do direito de moradia com o escopo de traçar a relação existente entre os institutos. Pela análise constatou-se que o direito à moradia foi inserido formalmente na Constituição Federal de 1988, na condição de direito social, fortalecido pela Emenda Constitucional $n^{\circ}$ 26/2000. Contudo, mesmo antes da referida normatização o direito à moradia já poderia ser deduzido a partir do respeito ao princípio da dignidade da pessoa humana, ainda que entendido como o oferecimento do mínimo existencial.

Destarte, no tocante ao direito de propriedade e o direito à moradia existem distinções específicas para cada um dos institutos jurídicos. Logo, a efetivação do direito social à moradia não pressupõe a coexistência do direito de propriedade, sendo certo que a efetivação do direito à moradia pode ocorrer por meio de outros direitos públicos e privados, que não o de propriedade.

Assim, como o direito de propriedade não pode atualmente dissociar-se do cumprimento de sua função social, o direito à moradia não pode vir desacompanhado da palavra adequada. 
Nesse sentido, tem-se que a moradia não se restringe a unidade habitacional de forma isolada do contexto social. $\mathrm{O}$ direito à moradia adequada significa a unidade habitacional inserida num ambiente dotado de serviços e equipamentos urbanos que proporcionem a inclusão social no espaço da cidade sustentável.

Ressalta-se que, por força do que vem definido em cada um dos institutos aqui analisados, tendo em vista a natureza de direito fundamental do direito à moradia que o Estado deve promover políticas públicas que visem sua efetivação como corolário do próprio princípio da dignidade da pessoa humana.

Diante de todo o exposto, conclui-se que apesar da aparente colidência entre o direito de propriedade e o direito à moradia, ambos podem conviver de forma harmônica dentro dos ditames constitucionais, cumprindo a propriedade sua função social e viabilizando ao Estado o atendimento ao seu dever de prover e zelar pelos direitos e garantias fundamentais, em cujo cenário, certamente a sociedade fortalecer-se-á no ganho de cidadania digna, atendendo com equilíbrio a concretização do direito fundamental à moradia.

\section{REFERÊNCIAS}

BEVILÁQUA, Clóvis. Direito das Coisas. Coleção história do Direito Brasileiro. Brasília: Senado Federal, 2003.

BULOS, Uadi Lammêgo. Constituição Federal anotada. 5a ed., São Paulo: Saraiva, 2003.

CARVALHO, Natália. Metodologia cientifica. Marília: Fundação Unimed, 2007.

DINIZ, Maria Helena. Código Civil Anotado. São Paulo: editora Saraiva, 2003.

Saraiva, 2000, v. 4.

Curso de direito civil brasileiro: Direito das Coisas. 21 a ed. São Paulo:

FACCHINI NETO, Eugênio. Premissas para uma análise da contribuição do juiz para a efetivação dos direitos da criança e do adolescente, In: Juizado da Infância e da Juventude. Porto Alegre: Departamento de Artes Gráficas do TJRS, n. 2, mar. 2004.

nov.2006.

. A função social do direito privado. In: Revista Jurídica, ano 54, n. 349,

FILHO, Marçal Justen. Curso de Direito Administrativo. 2. ed. São Paulo: Saraiva, 2006.

LOPES, Miguel Maria de Serpa. Curso de Direito Civil: Obrigações. 7. ed. Rio de Janeiro: Freitas Bastos, 2006 
MACIEL, Heriberto Roos. Estado Contemporâneo: perspectivas da função social da posse, da propriedade e do direito à moradia no espaço urbano. Dissertação de mestrado. Unisinos, 2000.

MORAES, Alexandre de. Direitos Humanos fundamentais - teoria geral. $8^{\text {a }}$ ed. São Paulo: Atlas, 2007.

MONTEIRO, Washington de Barros. Curso de Direito Civil: Direito das Coisas. $37^{\text {a }}$ ed., São Paulo: Saraiva, 2003, v. 3.

PANSIERI, Flávio. Do Conteúdo à Fundamentalidade da Moradia. In: Constituição e estado social: os obstáculos à concretização da Constituição. Francisco José Rodrigues de Oliveira Neto (org.) São Paulo: Revista dos Tribunais; Coimbra: Editora Coimbra, 2008.

PEIXOTO, Marcelo Magalhães. IPTU - aspectos jurídicos relevantes. São Paulo: Quartier Latin, 2002.

RIZZARDO, Arnaldo. Direito das Coisas. Rio de janeiro: Forense, 2003.

SAMPAIO, José Adércio Leite. Direitos fundamentais: retórica e historicidade. Belo Horizonte: Del Rey, 2004.

SANTOS, Fernando Ferreira dos. O princípio Constitucional da Dignidade da Pessoa Humana. Fortaleza: Celso Bastos, 1999.

SARMENTO, Daniel. Direitos fundamentais e relações privadas. Rio de Janeiro: Lumen Juris, 2010.

SARLET, Ingo Wolfgang. A eficácia dos direitos fundamentais. $5^{\mathrm{a}}$. Ed. Porto Alegre: Livraria do Advogado, 2005.

Dignidade da Pessoa Humana e Direito Fundamentais na Constituição de 1988. $2^{\text {a }}$ Ed. Porto Alegre: Livraria do Advogado. 2010.

$O$ direito fundamental à moradia na Constituição: algumas anotações a respeito de seu contexto, conteúdo e possível eficácia. In: Revista do Direito do Consumidor, ano 12 , abr.-jun/03.

SEN, Amartya e KLIKSBERG, Bernardo. As pessoas em primeiro lugar. São Paulo: Companhia das Letras, 2010.

SILVA, Jose Afonso. Curso de Direito constitucional positivo. $20^{\mathrm{a}}$ ed., Sã Paulo: Malheiros, 2005.

SILVA, Virgílio Afonso. A constitucionalização do direito. São Paulo: Malheiros, 2009. STEINMETZ, Wilson. A vinculação dos particulares a direitos fundamentais. São Paulo: Malheiros, 2004

VENOSA, Silvio de Salvo. Direito Civil: Direito das Coisas. $6^{\text {a }}$ ed. São Paulo: 2004, v.5 